MATEC Web of Conferences 45, 01003 (2016)

DOI: $10.1051 /$ matecconf/20164501003

(c) Owned by the authors, published by EDP Sciences, 2016

\title{
Effects of Friction Stir Welding Speed on AA2195 alloy
}

\author{
Ho-Sung Lee ${ }^{1,2}$, Ye Rim Lee ${ }^{2+}$ and Kyung Ju Min ${ }^{1}$ \\ ${ }^{1}$ Korea Aerospace Research Institute, Republic of Korea \\ ${ }^{2}$ University of Science \& Technology, Republic of Korea \\ + currently at Korea Institute of Materials Science, Republic of Korea
}

\begin{abstract}
The application of friction stir welding (FSW) to aerospace has grown rapidly due to the high efficiency and environmental friendly nature of the process. FSW is achieved by plastic flow of frictionally heated material in solid state and offers many advantages of avoiding hot cracking and limiting component distortion. Recently low density, high modulus and high strength AA2195 are used as substitute for conventional aluminum alloys since the weight saving is critical in aerospace applications. One of the problems for this alloy is weld metal porosity formation leading to hot cracking. Combination of FSW and AA2195 provides synergy effect to improve mechanical properties and weight saving of aerospace structure such as cryogenic fuel tanks for launch systems. The objective of this paper is to investigate the effect of friction stir welding speed on mechanical and microstructural properties of AA2195. The friction stir welded materials were joined with four different tool rotation speeds (350 800 rpm) and five welding speeds (120 360 $\mathrm{mm} / \mathrm{min})$, which are the two prime welding parameters in this process.
\end{abstract}

\section{Introduction}

Friction stir welding (FSW) is a solid-state joining process, in which no solidification microstructures are produced so to eliminating the brittle phases common in fusion welding of high strength aerospace aluminum alloys $[1,2]$. In FSW, a rotating tool is pressed against the surface of two plates. The side of the weld for which the rotating tool moves in the same direction as the traversing direction, is commonly known as the advancing side (AS) and the other side, where tool rotation opposes the traversing direction, is known as the retreating side (RS). Frictional heat generated by rotation and traversing of the tool due to the high normal pressure and shearing action of the shoulder along the joint line causes a softened zone of material without melting. This softened material cannot escape outside as it is under constrained extrusion by the tool shoulder. As the tool travels along the joint line, material is moved around the tool probe between the retreating side of the tool and the surrounding non-deformed material. The mixed and extruded material is deposited to form a mechanically mixed joint in solid state behind the tool. The main process parameters are tool rotation rate and travelling speed along the welding direction. The rotation of the tool results in heating and mixing of the material around the pin. Therefore, higher tool rotation rates generate higher temperature because of higher friction heating and results in more severe mixing of material [3]. The travelling motion of the tool moves the mixed material from the front to the back of the pin. The details of the tool geometry are also important and are usually restricted from publication.

AA2195 is the third generation aluminum-lithium alloy and shows high specific strength (strength to density ratio). Lithium is the most effective addition to aluminum to reduce density and exhibits desirable precipitation hardening characteristics. Furthermore, the elastic modulus of the material is increased by each addition of Li. It also attain very high strengths with or without prior cold work, a necessity to attain the high strength tempers comparing to most aerospace aluminum alloys. Since this alloy is susceptible to hot cracking during fusion welding, a solid state welding, such as FSW, is adequate.

The purpose of the current study was to study the effect of friction stir welding speed on mechanical and microstructural properties of AA2195. Since FSW is both a deformation and a thermal process, temperature distribution during FSW is measured. The microstructure and mechanical properties of weldments were investigated for different welding conditions.

\section{Experimental}

The material used for this study is AA2195 which is obtained from Constellium Global Aerospace, France. The welds of this alloy were made on a three-axis milling machine equipped with a special fixture for friction stir welding. Two plates of $300 \mathrm{~mm}$ in length and $100 \mathrm{~mm}$ in width were joined by friction stir welding, in which one is for the advancing side (AS), and the other for the 
retreating side (RS). The welding direction was parallel to rolling direction. The range of welding parameter is four rotation speeds $(350,400,600$ and $800 \mathrm{rpm})$ and five travel speeds $(120,180,240,300$, and $360 \mathrm{~mm} / \mathrm{min})$. During welding, temperature distribution of welding area was monitored with K-type thermocouples with Kyowa UCAM-550A. Ten K-type thermocouples were set on the surface of the plates on a line $100 \mathrm{~mm}$ distant from the weld-start point to measure the temperature distribution. There are 3 thermocouples on the advancing side located at $100 \mathrm{~mm}$ from the start of welding and each 3 thermocouples are attached on advancing side and retreating side located at another $100 \mathrm{~mm}$. After welding, all of the specimens were inspected by $x$-ray radiography and one with defects are discarded. Tensile specimens with $200 \mathrm{~mm}$ long and $12.8 \mathrm{~mm}$ wide gauge part were cut along the welded joints and tested at room temperature using a $100 \mathrm{KN}$ MTS testing machine under displacement control. Metallographic specimens were prepared and JEM-2100F FE-TEM was used for electron microscopic study.

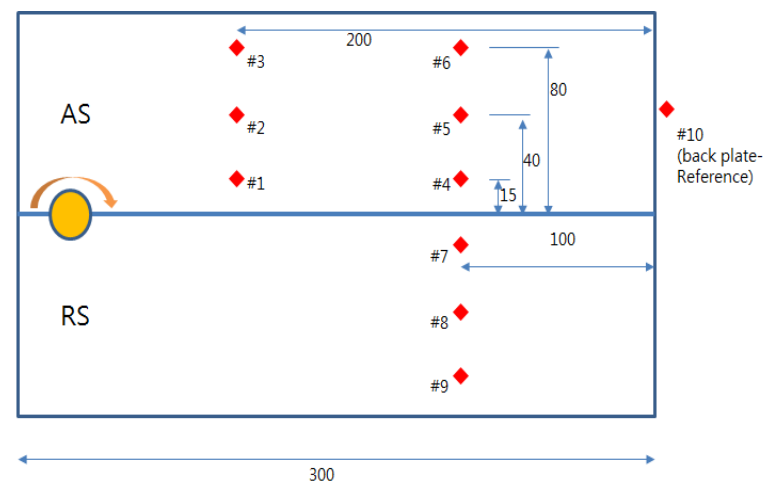

Figure 1. Location map of thermocouples

\section{Results and Discussion}

Figure 2 presents a typical grain microstructure of the joint welded at $400 \mathrm{rpm}$ with travel speed of $240 \mathrm{~mm} / \mathrm{min}$ showing a well recrystallized structure [4]. From upper part to the bottom part of the joint, the grain size tends to gradually decrease and this is because the heat dissipates through the back plate and results in fine recrystallized grains. The grain size in the advancing side is larger than that in the retreating side due to the heat input difference generated by the plastic deformation. Temperature measurement confirms the maximum temperature on advancing side is higher than that on retreating side as reported in literature [5].

Results of temperature measurement during FSW process are shown in Figure 3. General trend of temperature change is that higher tool rotation rate or lower traveling speed produce higher temperature. At the measurement from the specimen welded in $400 \mathrm{rpm}$ and $240 \mathrm{~mm} / \mathrm{min}$, the temperatures at \#1 and \#4 increased to over $205^{\circ} \mathrm{C}$ and the maximum temperature at $\# 7$ was $175^{\circ} \mathrm{C}$. It is notable that even though Tang [6] did not observe any temperature variation between the advancing and retreating side, recent study by Commin $[5,7]$ showed clear difference of temperature distribution between the advancing and retreating side, which supports the results of this study.

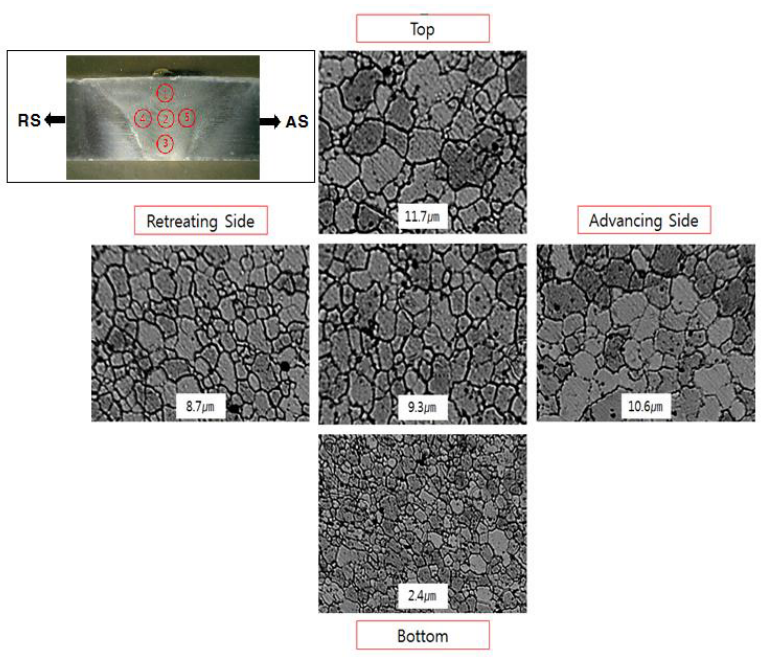

Figure 2. Grain structure of stir zone of typical joint welded at $400 \mathrm{rpm}$ with travel speed of $240 \mathrm{~mm} / \mathrm{min}$ [4]

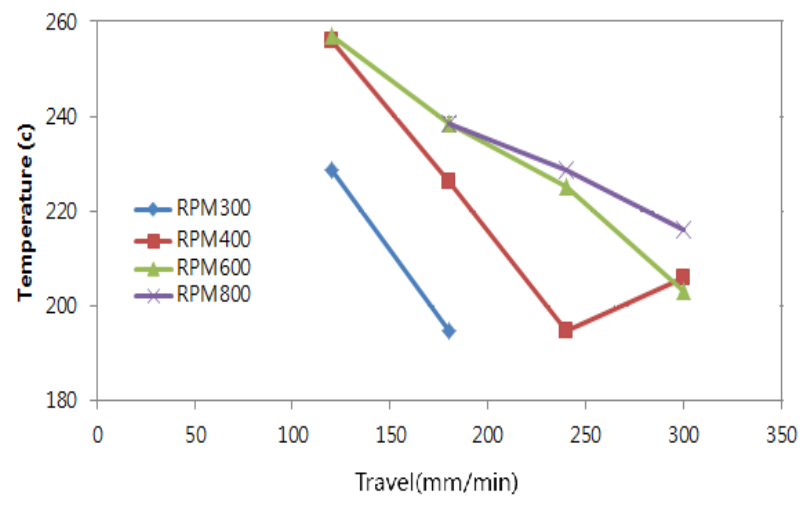

(a) Maximum temperature measured with different welding conditions

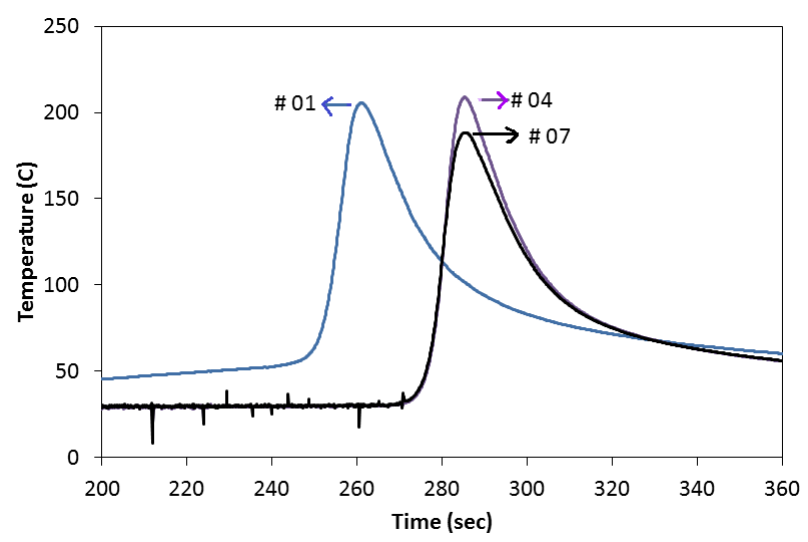

(b) Temperature profle at different location measured at 400 RPM and $240 \mathrm{~mm} / \mathrm{min}$ conditions

Figure 3. Results of temperature measurement during friction stir welding process

The experimental tensile properties of welded AA 2195 alloy joints are presented in Figure 4. Welded specimens from rotation rate of $350 \mathrm{rpm}$ are not 
presented here since the radiographic inspection detects relatively large amount of voids and therefore invalidated. The unwelded parent metal shows a tensile strength and elongation of $552 \mathrm{MPa}$ and $6 \%$, respectively. It is shown that the highest strength was obtained from the joint welded with rotation rate of $400 \mathrm{rpm}$ and traveling speed of $240 \mathrm{~mm} / \mathrm{min}$. The strength of the specimens welded at $400 \mathrm{rpm}$ are relatively insensitive to the traveling speed, while as that of the specimens welded at $800 \mathrm{rpm}$ decreases as the traveling speed increases. After inspecting the failure mode, it is shown that the specimens welded at $800 \mathrm{rpm}$ failed on advancing side of the joint and the specimen welded at $400 \mathrm{rpm}$ mostly failed on retreating side. The specimens failed on the advancing side generally show lower strength and this may be explained by the temperature difference between the two regions as mentioned earlier.

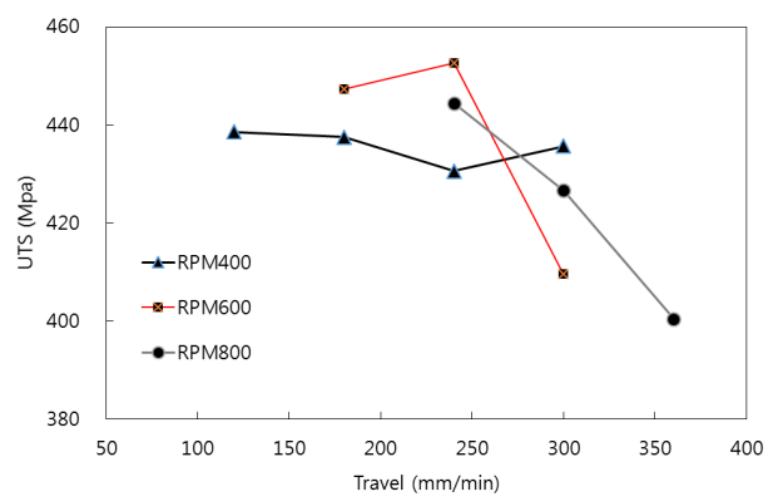

(a) Effect of welding travel speed on tensile strength

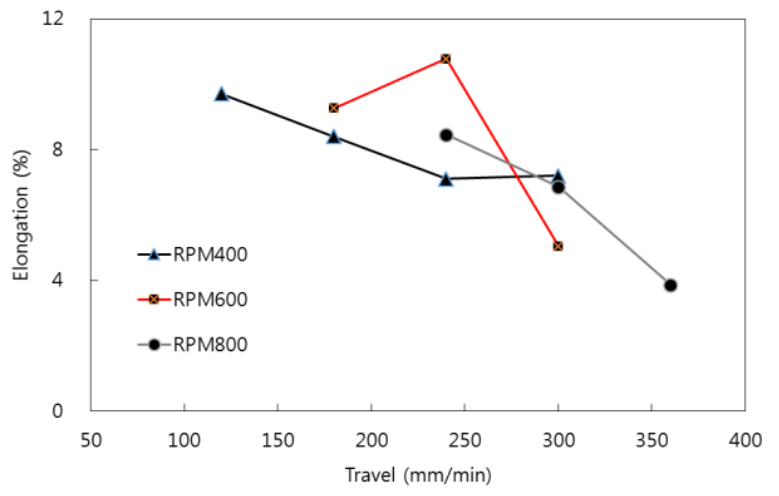

(b) Effect of welding travel speed on elongation of FSW joints

Figure 4 Effect of welding travel speed on mechanical properties of FSW joints

In Figure 5 is shown a TEM bright field image sampling microstructure at retreating side and advancing side for the joint welded with rotation rate of $400 \mathrm{rpm}$ and traveling speed of $240 \mathrm{~mm} / \mathrm{min}$. In retreating side, smaller precipitates are aligned in the elongated grain boundaries and the size of precipitates in advancing side is larger than that in retreating side. The results of TEM microstructural study will be published elsewhere [8]. There are still some controversy in microstructure study of stir zone. In the previous study of $\mathrm{Li}$ [9], no $\mathrm{T}_{1}$ was observed, but $\mathrm{T}_{\mathrm{B}}$ was observed in the stir zone. This was supported by Oertelt [10]. Howerer, Schneider, et. al. presented coarse $\mathrm{T}_{1}, \theta^{\prime}$, and $\mathrm{T}_{\mathrm{B}}$ precipitates were observed in the stir zone [11]. Shukla studied in detail the evolution of precipitates in friction stir welds and observed different levels of $\mathrm{T}_{1}, \theta^{\prime}$ dissolution in the heat affected zone and thermo-mechanical affected zone [12]. Further TEM study is on-going to investigate the effect of traveling speed on the precipitation.

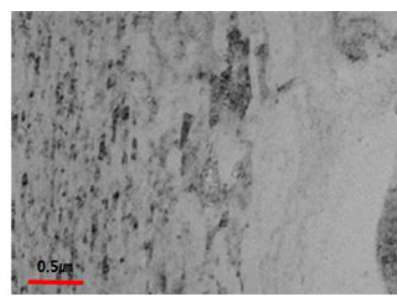

(a) Retreating side

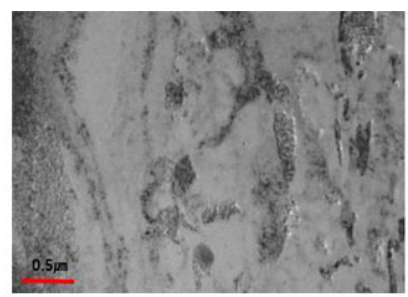

(b) Advancing side
Figure 5. TEM photographs after friction stir welding [4]

\section{Conclusion}

The effect of friction stir welding speed on mechanical and microstructural properties of AA2195 is investigated. The materials were joined with four tool rotation speeds and five welding speeds. It is shown that the recrystallization has resulted in very fine grain in the region adjacent to the back plate. It is confirmed that the grain size depends on the amount of the heat input which is a function of rotating rate and traveling speed. Difference of temperature distribution between the advancing and retreating side is reported to support the Commin's work $[5,7]$. The effect of welding speed is sensitive to the mechanical properties of the specimens welded at $800 \mathrm{rpm}$, which failed on advancing side of the joint. It is shown that the highest strength was obtained from the joint welded with rotation rate of $600 \mathrm{rpm}$ and traveling speed of $240 \mathrm{~mm} / \mathrm{min}$.

\section{References}

1. S. Shah, J. Wagner, and H. Bable: Thermal Exposure Effects on Al-Li Alloy Plate Products. Presented at the 14th Annual Advanced Aerospace Materials and Processes Conference, Dayton, OH, June 10, 2003.

2. D. E. Glass, Airframe Technology Development for Next Generation Launch Vehicles, IAC-04-V.5.09.

3. R. S. Mishra, M. W. Mahoney, S. X. McFadden, N. A. Mara, and A. K. Mukherjee, "High strain rate superplasticity in a friction stir processed 7075 al alloy," Scripta Materialia, 42, 163 (2000)

4. Y. R. Lee, Effect of process parameters on friction stir welds of AA2195, M.S. Thesis, August 2015, University of Science \& Technology at Korea.

5. L. Commin, M. Dumont, J. Masse, and L. Barrallier, Acta Materialia, 57 326-334 (2009)

6. W. Tang, X. Guo, J. C. McClure, and L. E. Murr, J. Mater. Process Manufac. Sci, 7163 (1998) 
7. M. Maeda, L. Huijie, H. Fujii, and T. Shibayanagi, Welding in the World, 19 69-75 (2013)

8. J. H. Kim and H. S. Lee, submitted to J. Alloys and Compounds.

9. Z. X. Li, W.J. Arbegast, P.J. Hartley, E.I. Meletis, in: Proceedings of the Fifth International Conference on Trends in Welding Research, Pine Mountain, Georgia, June 1998, ASM International, Materials Park, Ohio, 568.

10. G. Oertelt, S. S. Babu, S. A. David, E. A. Kenik, Weld. J. 8071 (2001)

11. J. A. Schneider, A. C. Nunes Jr., P.S. Chen, G. Steele, J. Mater. Sci. 404341 (2005)

12. A. K. Shukla and W. A. Baeslack, Sci. Technol. Weld. Join. 14376 (2009) 